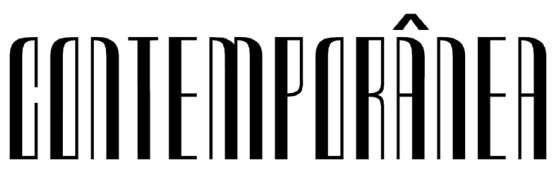

ISSN (Eletrônico): 2316-1329

http://dx.doi.org/10.4322/2316-1329.011

Contemporânea

v. 6, n. 1, p. $51-73$

Jan.-Jun. 2016

Dossiê

\section{Práticas e dispositivos: escalas, territórios e atores}

Isabel Pauline Hildegard Georges ${ }^{1,2,3}$

Cibele Saliba Rizek ${ }^{2,3,4}$

Resumo: O artigo discute dimensões teórico metodológicas provenientes de pesquisa etnográfica de média duração na periferia leste da cidade de São Paulo. As políticas sociais de saúde, habitação, transferência e geração de renda e seus modos de operação apontam para configurações importantes de práticas, atores e territórios que redesenham concepções e relações entre o estado e populações, entre práticas e sociabilidades apontando para enfoques e questões de pesquisa numa reflexão sobre seus resultados.

Palavras-chave: politicas sociais e política; estado; praticas; escalas; atores.

\section{Practices and devices: scales, territories and actors}

Summary: The article discusses theoretical and methodological dimensions from ten years of ethnographic research in the eastern outskirts of the city of São Paulo. Social policies in health, housing, transfer and income generation and their modes of operation point to important settings of practices, actors and territories and

\footnotetext{
${ }^{1}$ Développement et sociétés (DEVSOC) - Institut de Recherche pour le Développement (IRD) - Nogent-sMarne - França - isabel.georges@ird.fr

${ }^{2}$ Centro de Estudos dos Direitos da Cidadania (Cenedic) - Universidade de São Paulo (USP) - São Paulo - Brasil ${ }^{3}$ Programa de Pós-graduação em Sociologia (PPGS) - Universidade Federal de São Carlos (UFSCar) - São Carlos - Brasil

${ }^{4}$ Instituto de Arquitetura e Urbanismo (IAU) - Universidade de São Paulo (USP) - São Carlos - Brasil - cibelesr@ uol.com.br
} 
redesign concepts and relations between the state and the poor populations, between practices and sociability, requiring new approaches and research questions and a reflective examination of their results.

Keywords: social policies and politics; state; practices; scales; actors.

Esse texto, elaborado a quatro mãos, resulta da tentativa de compreender uma pluralidade de dimensões articuladas como resultado de incursões etnográficas, para além dos procedimentos clássicos de generalização e apreensão de tendências sociais exclusivamente como resultado do tratamento estatístico de grandes bases de dados 5 . Se essa articulação foi estabelecida a posteriori, isto é, a partir de um conjunto de reflexões que vieram das interconexões entre momentos e temas de pesquisa, foi com base nesses esforços de observação, entrevistas, incursões que se pôde acumular e compreender um mosaico de situações e seus feixes de interconexão. Os fios entre elas apontam para uma teia que acaba por impor como temas e questões a intersetorialidade das práticas (o que permitiu compreender nexos importantes), redes de atores e modos de operação de programas e políticas, territórios e territorialidades que se cruzam com ou sem superposições. Essas dimensões se impuseram como questões e problemas de pesquisa para além do recorte e da construção dos objetos específicos, que nos conduziriam a campo, em cada momento. Por consequência, um conjunto de dimensões teórico-metodológicas se desenhou como resultado dessa reflexão porque, ao recortar objetos de pesquisa, ao entrelaçá-los, atira-se no que se vê e acerta-se no que, pelo menos de forma imediata, não se vê. As conexões, a possibilidade de sua apreensão, as relações que pudemos apreender e tematizar resultaram do que pudemos identificar como incursões etnográficas em um território, em um espaço delimitado da periferia leste da cidade de São Paulo que se constitui como ancoragem, como ponto nodal de cruzamento de redes de práticas e atores, de apreensão de dimensões que se conformaram, em um primeiro momento, como estritamente locais e cuja apreensão e compreensão exigiram deslocamentos de escala, para além dos níveis estritos de investigação micro ou macro.

Assim, talvez como descoberta, alguns dos territórios se desenharam ou emergiram como questão a partir das práticas e dimensões observadas - elas também - a partir de incursões e visitas, trajetórias, relatos de vida entrecruzados. Desse ponto de vista, é possível apreender a construção etnográfica dos territórios tanto pela sua presença forte - contiguidade, ancoragem de práticas, proximidades

\footnotetext{
${ }^{5}$ Uma versão dessas ideias compõe o texto apresentado por Isabel Georges, "Informalidades do Estado e dispositivos de ordenamento: Uma abordagem territorial, setorial e comparativa", comunicação no $38^{\circ}$ Encontro Anual da Anpocs em Caxambu, MG, em 2014, no GT 34 "Sobre Periferias"; outro conjunto de considerações metodológicas foi escrito pelas duas autoras para o seminário final do projeto ANR Les Suds II LATINASSIST "Gouverner les pauvres en Amérique Latine: gérer les femmes par l’assistance", em fevereiro de 2014, Nogent-sur-Marne.
} 
- como a partir da ausência dessas dimensões como índices, por exemplo, de certa externalidade que, por vezes, pode se tornar um dos elementos significativos de pesquisa. De qualquer modo, pode-se indicar parte dessas conexões pela presença ou pela ausência, mais uma vez como um procedimento de pesquisa a partir e em razão de relações de proximidade territorial entre práticas e atores, entre nexos, ou de sua inexistência ${ }^{6}$. Pela presença e pela falta, as dimensões territoriais acabam por constituir um elemento cheio de sentidos e significações, amplificados por um lado por práticas que se conectam territorialmente - práticas que constituem territórios do ponto de vista da experiência dos atores e sujeitos - ou ainda do ponto de vista de forças estruturantes de localização, quase sempre múltiplas, que se articulam ou que apenas se justapõem.

Assim, as relações entre a ideia, tanto de dispositivo quanto de agenciamento, e sua ancoragem territorial talvez possam ser pensadas em suas múltiplas intersecções. Dessa perspectiva é preciso mencionar que, ao longo de um conjunto nada homogêneo de incursões a campo, perseguindo pistas de pesquisa a propósito de objetos de investigação diversos entre si, pudemos apreender processos cujo nexo extrapola cada recorte empírico, cada pesquisa em particular ${ }^{7}$. Trata-se de pensar o que poderia ser identificado - no jogo interescalar, assim como no entrelaçamento temporal de processos de pesquisa diversos entre si - como "regimes de visibilidade", que permitem (ou não) perceber e compreender dimensões da formulação, ação e formas de operação do Estado, esse "fazer estado nas margens" a que se refere V. Das; apreender e compreender sentidos que põem em xeque e em questão formas de operação que se contaminam e se cruzam entre políticas e programas diversos; apreender capilaridades e enovelamentos entre dimensões que conformam campos de pesquisa distintos entre si, como políticas sociais, práticas e concepções religiosas, programas de assistência, de cultura, de moradia e habitação, o chamado "mundo do crime", entre outras dimensões.

Assim, o não nomeado - que não se desenha ou se desenhou como objeto das incursões a campo e, ao mesmo tempo, o que seria identificado apenas e necessariamente a partir das incursões a campo, a partir das conexões e da

\footnotetext{
${ }^{6}$ Note-se especialmente, o exemplo de uma importante Ong local, responsável pela implementação de um conjunto de programas e políticas sociais, que desconhecia inteiramente um grande empreendimento vinculado ao Minha Casa Minha Vida que estaria para ser implementado ao lado de uma de suas subsedes.

A pesquisa de campo que está na base da elaboração do diálogo de pesquisa entre as duas autoras foi realizada no âmbito de diversos convênios bilaterais franco-brasileiros e internacionais, por momentos em parceria com Yumi Garcia dos Santos (UFMG): "As novas configurações do trabalho e trajetórias de inserção de populações de baixa renda”, CNPq-IRD, 2007-2011, coordenado por M. de Paula Leite e I. Georges; "A nova gestão da questão social no Brasil: Entre participação e mercantilização", CNPq-IRD, 2011-2015, coordenado por J. C. Lima e I. Georges; “Emergência e reinvenção: 'Novas' e 'velhas' políticas sociais no Brasil”, CNPq-IRD, 2013-2017, coordenado por C. S. Rizek e I. Georges, e o projeto de cooperação internacional "Oferta institucional e lógicas de atores: Mulheres assistidas em seis metrópoles da América Latina”, Latinassist ANR Les Suds II, 2011-2014, coordenado por B. Lautier e, posteriormente, por B. Destremau e I. Georges. Além desses projetos, a investigação já concluída com o título "O Social e o Cultural entrelaçados" (CNPq B Produtividade em Pesquisa 2011-2014), a pesquisa Edital MCidades n. 11/2012, "A MCMV-entidades no estado de São Paulo. Abordagem etnográfica de casos selecionados", coordenada por Cibele S. Rizek, com a participação de Caio S. de Carvalho, Camila Moreno Camargo, Andrea Q. Castro, entre outros pesquisadores.
} 
extensão dos achados de pesquisa -, se transforma em novas questões, permitindo prospecções e projeções sobre novos objetos. Esses elementos podem encontrar amparo nas discussões relativas à pesquisa etnográfica multissituada e estendida tal como formulada por Burawoy ${ }^{8}$ ou mesmo na Grounded Theory (Glaser; Strauss, 1967), tal como também apontou Burawoy (2000).

É ainda importante mencionar que o presente texto é fruto de pesquisa coletiva, de média/longa duração, que teve início com o conjunto de incursões a campo que deu origem ao livro Saídas de Emergência: Ganhar/perder a vida na periferia de São Paulo e que desencadeou outros projetos, novas equipes, novos desdobramentos, sobre os quais esta reflexão se debruça.

\section{Alguns exemplos/cenas/situações de pesquisa}

Início do milênio - das novas formas de trabalho às injunções Estado / cooperativas/ associaçõos

Nossos primeiros textos resultaram de uma investigação a respeito das relações entre trabalho "precário" e cidade, e de um conjunto de incursões de pesquisa em um mesmo bairro (Georges; Rizek, 2008, 2012; Rizek, 2010). Entre outras dimensões, algumas questões e desdobramentos ficariam explícitos: a primeira é a distância e as dificuldades relativas à mobilidade urbana como condição daquilo que identificamos - a viabilidade e plausibilidade do trabalho sem registro, sem garantias, sem carteira, supostamente vinculado a uma cooperativa orquestrada a partir de uma associação de moradores que só poderia acontecer ali - em Cidade Tiradentes, onde qualquer outra alternativa suporia ou a mesma precariedade de vínculos e de rendimentos salariais ou a dura e interminável mobilidade para outros pontos da cidade onde seria possível, mas talvez mais difícil, obter alguma renda. $\mathrm{O}$ achado de pesquisa - que se conformava em meio a visitas a Cidade Tiradentes acompanhando Robert Cabanes - era uma "falsa" cooperativa de costura cujo regime de trabalho (em que eram evidentes o assédio moral, o uso abusivo do poder de coerção sobre os trabalhadores, demissões arbitrárias, entre outros traços de despotismo presente no cotidiano da cooperativa) conduziu à pergunta sobre as razões do uso da costura como suposta "alternativa de geração de emprego e renda". Essas razões se assentavam na combinação local de saberes e práticas que permitiam, em uma condição semelhante à do trabalho em domicílio "clássico", um adensamento da exploração e do uso do trabalho predominantemente feminino. A proximidade dessa prática feminina - e, quando necessário, também masculina - de costura, adquirida como qualificação tácita que já vinha tendo lugar nos apartamentos exíguos dos conjuntos habitacionais de Cidade Tiradentes, permitia o uso de capacidades desenvolvidas a partir dos processos de construção de gênero e exigia quase nada de investimentos prévios, além da qualificação das

\footnotetext{
${ }^{8}$ Ver Global Ethnography.

${ }^{9}$ Cabanes et al. (2011).
} 
mulheres, trabalhando em casa, para a entrega de peças bordadas, costuradas, com apliques ou etiquetadas com marcas de prestígio - verdadeiras ou "falsificadas", combinando "formalidades e informalidades", legalidades e ilegalismos, em circuitos de práticas de produção e comercialização (Silva, 2008; Georges; Silva, 2007; Rizek; Georges; Silva, 2014; Rizek, 2013).

Assim, costura e reciclagem - em especial a que tem lugar nas pontas mais precárias do bairro, as favelas Jardim Maravilha e Buraco do Gato - pareciam ser as únicas possibilidades plausíveis até aquele momento para uma grande massa de moradores e moradoras de Cidade Tiradentes. A proximidade do local de moradia era o grande trunfo dessas duas possibilidades que, dessa perspectiva, tornavam-se funcionais tanto para seus respectivos circuitos como para a população que delas necessitava para a própria sobrevivência.

O que essas incursões de pesquisa detectaram foi basicamente uma dimensão invisível das relações e formas de trabalho embaralhando circuitos e territórios, mas também entre trabalho associado e trabalho assalariado, próximo do que alguns autores identificam como "precariado" (Braga, 2012). Antigos "bairros dormitórios", produzidos por conglomerados de pequenos apartamentos financiados por programas de habitação social, assim como loteamentos populares frequentemente irregulares e autoempreendidos nas fronteiras leste da cidade de São Paulo, transmutaram-se em novos territórios produtivos (Rizek, 2012), ainda que não seja possível observar nenhuma unidade industrial em pleno funcionamento ${ }^{10}$. Assim, Cidade Tiradentes - um bairro produzido pelo Estado, a 35 quilômetros do centro da cidade - pode ser compreendida como um nó em um circuito de produção de confecções, dentro e fora dos apartamentos, em garagens improvisadas, em cooperativas. Sua produção chegaria a grandes lojas de consumo popular ou de luxo, na feirinha da madrugada ou nos empreendimentos do Ministério dos Esportes. Haveria ali um conjunto de novas e velhas possibilidades de trabalho que se desenvolveriam de modo mais ou menos invisível. Nas relações de trabalho supostamente cooperativadas, ganhou corpo, tal como constatamos em campo e em textos posteriores, a possibilidade de exploração e absorção das parcelas de trabalhadores mais vulneráveis - mulheres negras, idosas, mulheres chefes de família em situações de muita precariedade, presidiários, "autônomos". $\mathrm{Na}$ cooperativa foi possível observar as etapas de confecção de camisetas, bolsas, bonés e bandeiras para atividades esportivas oficiais, inclusive as bandeiras brasileiras que os atletas exibiram nas Olimpíadas de Pequim ${ }^{11}$.

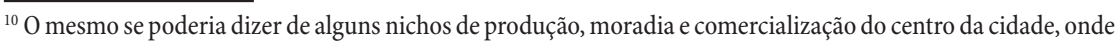
pululam oficinas de costura e seus trabalhadores, que frequentemente moram e trabalham em situações-limite, elas também dificilmente passíveis de serem descritas como trabalho em domicílio. Na verdade, pode-se afirmar que a categoria trabalho em domicílio não se aplica inteiramente a essas situações, em especial as oficinas cujos trabalhadores são bolivianos não documentados. Se o trabalho em domicílio supunha atividades realizadas nos locais de residência dos trabalhadores, trata-se aqui do contrário: esses trabalhadores habitam os locais em que trabalham (Rizek; Carvalho; Camargo, 2014).
}

${ }^{11}$ Georges e Rizek (2008, 2012) e Rizek (2012). 
As ambiguidades e dobraduras, as articulações e o modo pelo qual essas populações enfrentam suas condições de trabalho e de vida, trouxeram ainda elementos surpreendentes: trata-se da constituição de um mix, também ele da ordem das indiferenciações, entre trabalho social, trabalho associado (ou pelo menos autodefinido como tal) e trabalho assalariado, nas suas formas menos reguladas e mais precárias ${ }^{12}$.

Alguns desses primeiros resultados substantivos apontavam para uma presença imprevisível e insuspeita das relações entre situações precárias e informais de trabalho e Estado. A cooperativa, proveniente de uma associação de moradores e mutuários, teria se viabilizado e prosperado produzindo material para um cliente em particular: um ministério do governo brasileiro, ocupado por um dos partidos da base aliada do primeiro governo Lula. Assim, em condições muito precárias de trabalho supostamente associado era possível ler a inscrição símbolo dos governos do PT - Brasil um país de todos - estampada nas camisetas e em outros produtos fabricados em regime de relações de trabalho informal mas, sobretudo, precário e despótico.

Foi então possível detectar o lugar de um dentre muitos diferentes modos de informalidade e precariedade nas dobraduras da ação do Estado, um primeiro sentido das relações informais de trabalho como parte do leque de informalidades do Estado que acabaria por reforçar e se utilizar dos "dispositivos de ordenamento" vigentes no território das periferias das grandes cidades brasileiras, a partir dos seus mecanismos de funcionamento e suas intersecções com outras relações sócio-espaciais, outros modos de ordenar e territorializar sociabilidades. É possível, assim, remeter essas dimensões à contribuição de Antônio Machado da Silva (2014) sobre o que estaria por traz da resiliência da categoria do informal, apesar do seu aparente esgotamento e de sua transformação em continente de múltiplos conteúdos ou, como aponta Machado, em categoria “ônibus". Trata-se de constatar que a presença do Estado não significa necessariamente o aumento de formalização (e, mesmo se houver, essa presença não institucionaliza necessariamente situações de trabalho "virtuosas", cf. Georges, 2015, entre outros).

Esse ponto de partida analítico revelou que a forte presença direta do Estado no âmbito local, através de programas diretos do governo federal, com enorme visibilidade política, podia não significar garantia de acesso aos direitos (expressão usada por um gerente das políticas de assistência, participante das conferências municipais de assistência da qual participamos) no sentido de sua universalização. Ao contrário: a constatação era de uma institucionalização de jogos de poder, por meio de distribuição de favores e consolidação de um mercado eleitoral para

\footnotetext{
${ }^{12}$ Há aqui uma questão de nomeação que não se pode deixar de assinalar. As palavras precariedade e informalidade, entre outras, que apontavam para uma característica não regulada e vulnerável das situações de trabalho, portanto, para uma característica negativa da inserção produtiva de camadas populares, parecem não dar mais conta da gigantesca diversidade e multiplicidade de situações que se abrigavam sob essas denominações. Continuamos, entretanto, utilizando os mesmos termos, ainda que reconheçamos sua insuficiência.
} 
partidos aliados ${ }^{13}$. Nesse sentido, esse primeiro experimento de inserção no campo de pesquisa devidamente transformado em problema teórico e empírico funcionou como um "choque" que orientaria nosso olhar. Alertou para a função do Estado como intermediador de ilegalidades/ilegalismos, criador de "informalidades" e precariedades sob o manto de programas de economia solidária e de iniciativas de geração de emprego e renda que perpassavam e constituíam situações despóticas de trabalho dentro de um circuito produtivo e político que se enreda na constituição nada virtuosa de um social recriado ${ }^{14}$.

\section{Saúde e cultura: privatizações cruzadas}

Nesse mesmo território, bem como nos bairros mais consolidados da periferia leste, também a partir de incursões etnográficas, outro achado surpreendente, explorado em textos também já publicados (Rizek, 2013; Georges, 2014, 2015), apontava para dimensões territoriais diversas entre si, que se articulavam onde tínhamos concentrado esforços de pesquisa. Acompanhando pesquisadores que estavam às voltas com os modos de operação dos programas de saúde (Georges; Santos, 2016), um outro conjunto de achados acabou por tomar corpo, colocando desafios muito interessantes: por um lado, a dimensão multiescalar - a necessidade de deslocamentos escalares impostos pelos desafios de pesquisa que a partir de então se colocavam. Por outro, o fato de que esses achados foram possíveis necessariamente a partir das dimensões e incursões de pesquisa centradas em um mesmo território. Trata-se do que pôde ser nomeado como privatizações cruzadas, as quais apontavam para uma proposição e uma política de implementação de serviços de saúde e de cultura que teve na experiência paulista e paulistana um de seus pontos nodais.

A partir da Organização Social a cargo dos serviços de saúde em todo território do extremo leste da cidade de São Paulo foi possível puxar os fios de uma trama que permitiu perceber de que modo a privatização do financiamento e gestão da cultura e da saúde se entrelaçaram, alcançando, por um lado, a permanência intocada de políticas culturais de cunho federal que datavam dos anos 1990 e foram se atualizando ao longo das duas décadas dos anos 2000; e, de outro, as políticas de terceirização em todos os âmbitos de atenção à saúde levada a cabo de modo pioneiro pelos governos de São Paulo (estado e municípios) (Georges, 2011; Georges; Santos, 2016; Rizek, 2013). Esse cruzamento das atividades e instâncias culturais e dos diferentes níveis de atenção em saúde nas mãos do mesmo grupo de gestores também permitiu interrogações e problematizações que, a partir de um território específico e de um olhar voltado para os programas sociais, tornaram

\footnotetext{
${ }^{13}$ Note-se que a zona leste representa um forte contingente populacional, de uma população pobre, que vota tradicionalmente "à esquerda". Foram frequentes as menções à obrigatoriedade de participação dos trabalhadores dessa "cooperativa" dos atos e manifestações do PcdoB, que estava à frente do Ministério dos Esportes à época. Essa também era a filiação partidária dos gerentes e promotores da iniciativa de "trabalho associado". Ver Georges e Rizek (2008).

${ }^{14}$ Ver a esse respeito Rizek (2016). No texto a autora se apropria da noção de invenção do social tal como formulada por Paulo Arantes na entrevista concedida à Revista Caros Amigos, fevereiro de 2015.
} 
possível apreender fenômenos que dizem respeito à gestão da vida, à "trama dos viventes"15 e a um conjunto de dispositivos articulados naquele território específico. Esses múltiplos cruzamentos permitiram compreender dimensões que enovelavam fluxos decisórios, de financiamento e de formulação que apontavam para um quadro estruturante da gestão da vida por meio do governo dos pobres - de seus corpos e condutas - que se desdobra na instituição de uma moral dos pobres, em práticas e representações que pudessem conformar a figura exemplar do bom pobre, aquele que merece se tornar beneficiário dos programas sociais redistributivos (Lautier, 2009, 2014; Georges; Rizek; Ceballos, 2014; Destemau; Georges, 2016).

Achados de pesquisa durante as incursões etnográficas realizadas em Cidade Tiradentes e Guaianases entre 2011 e 2013 tiveram como subproduto a percepção a princípio inusitada de indícios que apontaram para um conjunto de novas formas de captação de recursos, por meio de eventos, práticas culturais e de gestão de serviços privatizados de saúde na Zona Leste da cidade de São Paulo. O cruzamento entre modos de captação, gestão terceirizada da cultura e de ações e equipamentos de saúde apontaram para a intersetorialidade dessas práticas, conformando o que poderia ser identificado como um planejamento social privado minucioso por parte de Organizações Sociais de Cultura e de Saúde, que pareciam redesenhar formas de atuação e margens do Estado nas suas relações com programas sociais e com a população paulistana dos bairros mais pobres, especialmente a leste da cidade. Alguns desses bairros conformaram assim um território de experimentações dessas práticas cruzadas para além das caracterizações clássicas das zonas periféricas das grandes metrópoles [...] Talvez esses achados de pesquisa apontem para conformações diversas, modelizações diversas de construção e gestão do social no âmbito das gestões lulistas e petistas e das gestões do conglomerado de partidos nucleados pelo PSDB. Talvez se possa afirmar que estamos diante de duas formas de invenção e gestão do social, embora com pontos de contato, enovelamentos por vezes pouco passíveis de distinção ${ }^{16}$ (Rizek, 2016).

A partir das incursões a campo, foi possível perceber a formação de um terreno fértil para a ação de grupos e de empreendimentos privados que, crescendo em

\footnotetext{
${ }^{15}$ Menção ao título do livro Dispositivos urbanos e trama dos viventes: ordens e resistências. Birman et al. (2015).

${ }^{16}$ Ver a, esse respeito, a entrevista de Paulo Arantes já mencionada. Depois de afirmar que o PT e o petismo inventaram um social no Brasil, distinto dos processos social-democratas, ele afirma: "falta mencionar, mas apenas mencionar, a terceira perna desse governo do Brasil que, em conjunto ou sucessivamente, tucanismo e lulismo consolidaram. A redescoberta da política, como se viu, deixando para trás como relíquia arcaica a política da luta de classes, em qualquer de suas duas versões antagônicas, liberal e socialista, recebeu sangue novo também da reviravolta gestionária do mundo corporativo, que por seu turno também reinventou o social, mais exatamente a responsabilidade social, e tudo o mais que daí se segue, anunciando que a política dos políticos era mesmo o que as pessoas pensavam, um lixo. E tudo com muita participação e sociedade civil ativa e propositiva. Perversa ou não, deu-se uma confluência inédita com o aparato estatal e adjacências operando segundo a mesma lógica gerencial. Não é que a reinvenção petista da política tenha sido anulada ou sequestrada, simplesmente seus futuros parceiros se puseram em movimento ao também se darem conta que seu público-alvo se movera. Juntando as três pernas dessa fórmula tripartite de governo do país, teremos enfim identificado, na sua real natureza de tecnologia social de poder, o famigerado neoliberalismo. O PT foi um de seus inventores". Rizek, 2016).
} 
espiral, ofereciam, geriam e promoviam serviços, ações e práticas no campo das políticas sociais, de saúde e de assistência, dando origem à gestão empresarial do cotidiano e reconfigurando as relações entre Estado, serviços, populações e uma constelação de programas e políticas sociais e culturais que rearranjam em outra chave práticas de consumo, formas de sociabilidade e formas de expressão.

Em visitas a campo ocorridas entre 2010 e 2012 e a partir da sistematização de informações de pesquisa, a coincidência entre um conjunto de iniciativas de cunho cultural e a gestão de programas e equipamentos de saúde começou a se delinear como inquietação. Cruzavam-se escolas de música, faculdades, oficinas culturais, grandes eventos da agenda paulistana e hospitais, postos, agentes e programas de saúde e assistência à família, como práticas das organizações sociais e culturais capitaneadas pelo mesmo grupo, constatação que foi o ponto de partida de novas incursões a campo, bem como de novas questões de investigação $0^{17}$.

Algumas dimensões ganhavam força como elementos estruturantes do que se constatou em campo. A primeira foi a compreensão da gestão terceirizada dos serviços de saúde promovida pelas gestões Serra/Alckmin e Serra/Kassab, no município e no estado de São Paulo. Esses mecanismos de transferência de gestão da saúde do Estado para organizações sociais tiveram início a partir do final da gestão Erundina, em 1992 - e se estendem até hoje (Georges; Santos, 2016, capítulo 2 e 3; Rizek, 2013) ${ }^{18}$. A segunda dimensão decorria da presença concomitante de instituições encabeçadas por religiosas católicas tanto em hospitais e programas de saúde (como o Estratégia Saúde da Família) e seus equipamentos de ancoragem, que atendem a população que habita Cidade Tiradentes e outros

\footnotetext{
${ }^{17}$ Esse conjunto de achados de pesquisa dizem respeito especificamente a bairros da Zona Leste da cidade de São Paulo, sobretudo no que diz respeito à privatização e gestão dos equipamentos de saúde. Os achados de pesquisa iniciais que forneceram as pistas para uma incursão mais aprofundada na questão são provenientes de anos de acompanhamento de atividades e práticas em Cidade Tiradentes - no extremo leste do município, que pode ser caracterizada como um dos últimos bairros da cidade a se formar. Cidade Tiradentes ficou conhecida como "o maior conjunto habitacional da América Latina", tendo sido formada a partir de remoções provenientes de obras e de intervenções por toda a cidade de São Paulo. Apesar de inicialmente constituída por pequenos edifícios da $\mathrm{COHAB}$, o bairro cresceu a partir de combinações entre loteamentos e edifícios estabelecidos ou construídos de forma regular e pedaços de território ocupados irregularmente. A presença de assentamentos regulares ao lado de outros pouco ou nada regulares e/ou regularizáveis - favelas, habitações que se transformaram em estabelecimentos comerciais, edifícios da COHAB, terrenos e encostas também ocupados irregularmente, acabou por configurar uma população de cerca de 215 mil habitantes. $\mathrm{O}$ bairro cresce mais do que a média dos bairros paulistanos e tem cerca de $72 \%$ de sua população ganhando em média 2 salários-mínimos mensais (cf. São Paulo, 2012). Ao lado de Cidade Tiradentes, Guaianases é um bairro também constituído por populações de baixa renda e conta - somando-se a população de Lajeado com cerca de 25 mil habitantes. Esses bairros estão a cerca de $35 \mathrm{~km}$ do centro da cidade. Guaianases conta com o serviço de trens da CPTM e Cidade Tiradentes, apenas com serviço de algumas linhas de ônibus, reconhecidamente insuficientes para o transporte adequado da população. A partir de achados e informações dispersas, seguindo pistas e indícios, acabamos por perceber que grande parte dos equipamentos e serviços de saúde das periferias paulistanas estão sendo geridos por contratos com organizações sociais, como se constatará adiante. A especificidade dessas organizações identificadas no texto está assim no cruzamento entre as atividades de saúde e de cultura.
}

${ }^{18}$ A gestão Haddad não pôde alterar significativamente os contratos de gestão privada dos serviços de saúde da cidade. 
distritos da Zona Leste de São Paulo, como em ações, instituições e programas de cunho cultural que se estendem ao município como um todo.

Assim, para entender os processos que têm lugar no complexo de instituições de saúde geridas por essas organizações é preciso perceber como se enlaçam serviços e captação de recursos, por meio de um mecanismo de privatização da cultura e de terceirização dos equipamentos e serviços públicos de saúde, de modo entrecruzado ${ }^{19}$. Esse achado de pesquisa, ausente na literatura sobre cultura e saúde em São Paulo e no Brasil, parece constituir um caso em que se retroalimentam gestões e arbitragens privadas tanto das atividades culturais quanto de dimensões relativas à assistência à saúde, em suas injunções com a assistência social às famílias (Rizek, 2013; Georges e Santos, 2011, 2013, 2016; Santos, 2014). Trata-se de uma intrincada forma de engenharia organizacional que combina investimentos e aplicação de recursos, assim como setores, de forma bastante complexa, o que requer uma fina apreensão e manejo dos meandros dos processos de financiamento assim como uma perspectiva combinada que permita caminhar pelos processos de terceirização da saúde no estado- sede da privatização dos serviços públicos sob a égide dos governos do $\mathrm{PSDB}^{20}$.

Habitação e assistência: Da produção da "demanda" ao "governo moral dos pobres"

Moradia e demanda

O Programa Minha Casa Minha Vida foi apresentado como uma das grandes realizações dos governos Lula e Dilma e marcou as cidades brasileiras de forma indelével. No âmbito desse programa foram contratadas, até o início de 2014, 3,4 milhões de unidades habitacionais, das quais 1,7 milhão foram entregues. A pesquisa realizada sobre o programa teve como objeto a modalidade "entidades", que atende a chamada faixa 1, composta por famílias que recebem mensalmente até 1.600 reais. A produção dessa modalidade é contratada não por construtoras, mas por organizações populares, associações, cooperativas, que compõem o universo de "entidades" que se responsabilizam integralmente pela indicação das famílias e por todo o processo de produção - da pesquisa do terreno à entrega das chaves, passando por desenvolvimento e aprovação de projeto e execução das obras civis. Trata-se, de um lado, de uma produção ínfima em termos quantitativos, se comparada a toda produção do programa; de lado, a presença e permanência dessa modalidade tem uma dimensão política paradigmática, apoiando-se na tradição

\footnotetext{
${ }^{19}$ Em visita ao Hospital de Itaquera em maio de 2011, um dos responsáveis pelo serviço de oncologia pediátrica afirmou que a estratégia era a captação de recursos pelos grandes eventos culturais para a manutenção do serviço de ponta no hospital de Itaquera. Essa pista deu origem ao mapeamento desse texto.

${ }^{20}$ Essa confluência entre governos municipal e estadual foi um elemento importante para a captação e investimento que parece se configurar como fato consumado no Estado de São Paulo, mas que se desenha como tendência em outros estados e municípios do país, a julgar por algumas linhas de financiamento do Ministério da Cultura, em especial as que vinculam Saúde e Cultura. Ver os editais Cultura e Saúde e Rede Saúde e Cultura (Brasil, 2004, 2008).
} 
de políticas habitacionais autogestionárias, envolvendo os mais representativos movimentos de luta por moradia e reforma urbana do país ${ }^{21}$.

O PMCMV-Entidades apresentaria, então, os requisitos que caracterizaram a produção habitacional por autogestão à brasileira (ou o discurso sobre essa produção): os futuros beneficiários, potencialmente selecionados e conhecidos antes dos processos de obra, poderiam participar dos projetos e da execução, poderiam conhecer o terreno e seu entorno, opinariam sobre a concepção, acompanhariam o gasto de recursos, entre outras dimensões e supostas vantagens das formas de participação que possibilitariam a melhoria da qualidade das moradias. Esses processos, ricos e complexos, poderiam representar uma cunha no contexto geral do MCMV - majoritariamente destinado às construtoras e seus processos financeirizados de acumulaçãa ${ }^{22}$.

O desenvolvimento da pesquisa, entretanto, conduziu a constatações e conclusões que apontavam em sentido contrário a esses pressupostos potencialmente virtuosos. A primeira observação relevante foi a de uma corrida de obstáculos na qual a dimensão urbana desses conjuntos acabaria por se tornar secundária. Os empreendimentos do estado de São Paulo localizaram-se em terrenos comprados no mercado, em bairros periféricos precariamente consolidados ou nas franjas da mancha urbana metropolitana. Reproduziram, assim, de modo não raro agravado, a má localização dos empreendimentos que resultaram de outras modalidades de política habitacional em âmbito federal (os conjuntos do BNH, estadual ou municipal). Com o valor do terreno embutido no valor da unidade, acabou por prevalecer a lógica do terreno mais barato, que viabilizaria os empreendimentos.

Assim, o PMCMV-Entidades acabou por conduzir até mesmo os movimentos por moradia que lutavam por unidades habitacionais no centro da cidade, como 0 Fórum de Cortiços e o Movimento de Moradia no Centro (que mudou o significado do "C" de sua sigla, passando a se chamar Movimento de Moradia da Cidade) a uma busca de empreendimentos nos bairros periféricos Lajeado, Guaianases e Cidade Tiradentes. As dimensões dos terrenos "viáveis", pelo alto potencial construtivo ou pela quantidade de unidades a serem construídas, levaram a uma prática de "consórcios" de movimentos e associações. Além dessas associações entre movimentos de orientações diversas que, na prática, se consorciaram, as associações e entidades, necessariamente habilitadas junto ao Ministério das Cidades, muitas vezes com trajetórias e filiações políticas distintas, deveriam obrigatoriamente compor e constituir as "demandas", indicando famílias de suas bases, para que se viabilizassem conjuntos que chegam à marca de mil moradias,

\footnotetext{
${ }^{21} \mathrm{~A}$ pesquisa resultou de projeto submetido e aprovado em edital do Ministério das Cidades e do CNPq que envolveu, sob a coordenação de Cibele S. Rizek, pesquisadores ligados ao IAU (Instituto de Arquitetura e Urbanismo da Universidade de São Paulo - campus São Carlos) e à assessoria técnica Peabiru e que recortou as contratações e a produção realizada pela modalidade "Entidades" no estado de São Paulo, muito embora a sistematização de informações secundárias necessária para o dimensionamento e a reflexão sobre o programa tenha se estendido para o âmbito nacional. Alguns textos já publicados serviram de base para as considerações presentes nesse texto. Ver especialmente Rizek, Carvalho e Camargo (2014).
}

${ }^{22}$ Ver Shimbo (2012). 
dividindo o empreendimento em diversos contratos, para que fosse respeitado o limite de 300 unidades da normativa que regulamenta o programa.

Note-se ainda que esse processo permitiu (para não dizer induziu) a reconversão de entidades de outros campos de atuação social (a AMOVA, por exemplo, anteriormente dedicada à alfabetização de adultos) para o campo da habitação social. Associações e movimentos seriam transformados em máquinas de produção e/ou contratação de casas. O PMCMV-Entidades constituiu assim um enorme campo de consenso fora do qual parecia não haver saída para a conquista da moradia. Esse campo acabou por envolver até os movimentos que foram responsáveis pelas mais importantes ocupações de terrenos em São Paulo, como o Movimento dos Trabalhadores Sem Teto (MTST).

\section{Pobreza, assistência e demanda}

Entre 2010 e 2011 realizou-se uma pesquisa etnográfica sobre as formas de concretização das políticas de assistência social de "baixa complexidade" no município de São Paulo, por meio de observação participante e entrevistas biográficas $^{23}$, em uma Ong de cunho religioso neopentecostal (Georges; Santos, 2013). Situada em bairro mais consolidado da Zona Leste, a entidade/Ong/ associação/empresa moral era encarregada pela prefeitura do desenvolvimento do PAIF (Programa de Atenção Integral à Família), do Ministério do Desenvolvimento Social. Por meio de uma análise do "jogo de escalas" (Revel, 1996), surgiram, novamente, as articulações entre práticas e horizontes que se conformam como estatais, sociais e de mercado, ao longo da cadeia de produção do cuidado, com destaque para a "participação" como forma de legitimação da demanda social e para a instrumentalização do trabalho das mulheres, tanto no âmbito de suas famílias como do trabalho social precário.

No Brasil, o direito de acesso às políticas de assistência social - por meio do SUAS - Sistema Único de Assistência Social ${ }^{24}$ - ainda em vias de universalização - tem como principal modelo o SUS - Sistema Único de Saúde, criado em 1990. Nessa perspectiva de universalização do acesso aos serviços socioassistenciais, o PAF - Programa Ação Família foi implementado no município de São Paulo ${ }^{25}$ em 2005, por meio de terceirização empreendida por entidades da sociedade civil, com a supervisão dos CRAS - Centros de Referência de Assistência Social.

\footnotetext{
${ }^{23}$ As entrevistas foram realizadas com os usuários, agentes de proteção social, técnicos e gerentes. A pesquisa contou com 60 entrevistas, no total.

${ }^{24}$ O SUAS, por sua vez, ganhou o estatuto de lei em julho de 2011.É regulamentado pela NOB - Norma Operacional Básica desde 2005, a qual materializa as diretrizes da LOAS - Lei Orgânica de Assistência Social de 1993 e focaliza a família com base no território. Tal método de gestão tem se constituído em base operacional das políticas sociais durante a última década.

${ }^{25}$ O programa anterior, ProASF (governo Marta Suplicy), foi reformulado como Programa Ação Família -Viver em comunidade (2005), na gestão de José Serra, passando a ser chamado Programa Ação Família, em 2008. De acordo com os membros da equipe da unidade do PAF estudado, o programa tomou como referência principal o programa chileno PUENTES.
} 
A forma de operacionalização local do PAIF - Serviço de Proteção e Atendimento Integral às Famílias (inscrito no SUAS - Sistema Único de Assistência Social) por meio da intervenção de entidades da sociedade civil (no total, em São Paulo, cerca de mil Ongs e outras entidades cuidam do conjunto dos serviços assistenciais) constituiu-se no modo paulistano de lidar com a descentralização administrativa, a partir da lei de responsabilidade fiscal.

O exemplo estudado recebeu o nome fictício de Fundação Paixão - uma entidade sem fins lucrativos, uma ONG de cunho religioso, sediada na Zona Leste de São Paulo, que mantêm em 2010 vários convênios com a prefeitura, entre os quais o PAF pesquisado. Sua origem como igreja pentecostal remonta a 1979. Foi fundada por um médico, atualmente pastor da igreja. A gestão da ONG teria sido transmitida para seu filho. Hoje a igreja possui 6.000 fiéis em vários bairros da cidade de São Paulo, sendo que as 44 igrejas do território nacional contam com cerca de 20.000 a 30.000 fiéis. Internacionalizou-se recentemente, com uma igreja no Japão (destinada inicialmente aos imigrantes brasileiros) e outra na Espanha. Desenvolve um trabalho caritativo desde 1982, primeiro por profissionais voluntários da área médica da comunidade religiosa, nas salas adjacentes à igreja. Em 1996, transformada em ONG, contando com a contribuição decisiva do filho do fundador, médico ginecologista, vereador [...] durante vários anos e eleito deputado Estadual (PSDB) em 2010. Desenvolve o primeiro projeto caritativo com a comunidade no final dos anos 1990, (o) primeiro em parceria com uma outra entidade religiosa americana. No início dos anos 2000, assume [...] convênio com a prefeitura, cuidando de uma creche que foi retomada de uma outra entidade, que desviou recursos. Se em 2008, a Fundação emprega 70 trabalhadores(a)s formais (CLT), em 2010, eles(elas) são 280, mais 180 voluntários, que "doam" entre um ou dois dias de trabalho por semana à entidade. A gerência da entidade é composta por 13 pessoas, todos(as) membros da igreja, enquanto $30 \%$ do conjunto dos(das) trabalhadores(as) pertencem à igreja. A ONG é dirigida por um conselho, composto pelo presidente, vice-presidente, secretário, vice-secretário e tesoureiro; assim como por um conselho fiscal e curador.[...] O presidente atual, um empresário do ramo de bombas de extração, pastor voluntário da igreja ${ }^{26}$, é o antigo tesoureiro. Em 2010, a entidade mantêm oito projetos conveniados com a prefeitura: quatro creches, dois programas Ação Família, um restaurante para moradores em situação de rua "Bom Prato" na Lapa e uma casa de abrigo para mulheres em situação de violência doméstica. Na sede encontram-se igualmente uma policlínica e uma farmácia (distribuição de remédios [provenientes] de doação) focada na saúde da mulher assim como projetos assistenciais como a distribuição de leite e de cestas básicas. Desenvolve também um projeto de artesanato com mulheres do bairro e emprega duas costureiras. Também há um programa de penas alternativas e um projeto de apadrinhamento de crianças para o Natal. Entre os aproximadamente

${ }^{26}$ Mais que metade dos pastores da igreja são voluntários, sem remuneração, muitas vezes médicos e profissionais liberais; para os outros, ser pastor se tornaria ofício. Esses receberiam uma ajuda de custo. 
sete milhões de reais que circulam pela entidade por ano, $80 \%$ provêm dos convênios com a prefeitura, o restante sendo a "contrapartida" da instituição, oriunda de doações de membros da comunidade e de outras arrecadações (dízimo, resultado de bazares, etc. ${ }^{27}$, inclusive para providenciar os locais de desenvolvimento dos programas, não inclusos nos valores dos convênios (Georges; Santos, 2013: 162-163).

Desde 2011, cada unidade que operacionalizava o SASF - Serviço de Assistência Social às Famílias e de Proteção Básica no Domicílio (que substituiu o PAF - Progarma Ação Família, para se tornar um serviço permanente) seria composta por um(a) gerente, quatro técnicos com formação universitária e oito APS - Agentes de Proteção Social. Esses atendem cerca de 1.200 famílias por mês ${ }^{28}$, cada agente sendo responsável por 150 famílias. Os(as) agentes são mulheres, na sua maioria. As principais atividades desenvolvidas são as reuniões socioeducativas e as oficinas de "formação profissionalizante" (manicure, cabeleireira, artesanato, etc.), assim como as visitas domiciliares, cujo objetivo era o de orientar as famílias. O PAF, assim como o atual SASF, teria como atribuição a realização de um serviço de assistência social em domicílio, serviço de assistência que complementa, em tese, a recepção de diversos PTR - Programas de Transferência de Renda e de benefícios pelas famílias, como o Bolsa Família, o BPC - Benefício de Prestação Continuada, Aposentadorias, etc., oriundos tanto da esfera federal como provenientes do estado e/ou do município. A finalidade do PAIF e dos seus serviços acabou por se tornar objeto de negociação entre o governo municipal e as Ongs e entre essas e os usuários e, ainda, acabou por se tornar objeto de formas de apropriação diversas - que vão do controle das condicionalidades de benefícios sociais até a mobilização da população pobre nas suas reivindicações do acesso "ao ter direito aos direitos". Como outras políticas sociais, esses programas e serviços são de cunho "familista" (Mioto, 2010) e têm como eixo central a dimensão "socioeducativa". A maioria das pessoas atendidas pelo programa são mulheres pobres, assim como as trabalhadoras dos processos de implementação e acompanhamento. É preciso atentar, em particular, aos resultados e às formas de operacionalização desses programas e serviços que, embora não previstos, ganhavam concretude produzindo modos de governo e relações de gênero.

"No caso emblemático da Fundação Paixão (FP), essas práticas e mecanismos revelariam as formas de operacionalização de uma "gestão sexuada do social e da pobreza” nas políticas assistenciais contemporâneas voltadas

\footnotetext{
${ }^{27}$ Doações de pessoas físicas, principalmente através do Fumcad (até $1 \%$ do imposto, pelo qual o contribuinte pode definir a entidade que vai receber a doação), possibilidade de arrecadar o IPVA (pela obtenção do selo de entidade não-lucrativa, atribuído pelo governo federal).

${ }^{28}$ No caso do PAF pesquisado, a entidade atende quatro áreas com características sociodemográficas diferentes, todas no entorno da entidade, situada no norte do distrito de Itaquera. Dispõem de melhor equipamento em termos de infraestrutura e de transporte o setor I, em volta do Conjunto Habitacional Águia de Haia, que atrai inclusive uma população vinda de outros bairros da Zona Leste; e o setor II, pertencente ao Conjunto Habitacional A. E. Carvalho. Esses se contrapõem aos territórios da Vila Nova União, e de Vila Taquari, ambos formados principalmente por ocupações irregulares. São notáveis as diferenças entre os tipos de usuários, o tipo de serviço oferecido e a forma de atendimento em cada bairro.
} 
às famílias, através dos seus(suas) trabalhadores(as) e suas interações com as mulheres "assistidas", assim como o cruzamento das relações de classe e de gênero ao longo da cadeia de terceirização do serviço de assistência em análise - dos(das) gerentes aos(às) usuários(as) - e seus condicionamentos recíprocos. A gestão do social em questão é fortemente caracterizada pela presença feminina, mobilizando sua disposição em realizar o trabalho associado aos "cuidados" (Georges e Santos, 2012; Kergoat et al., 1992) e de encarregar-se das interfaces entre as esferas pública e privada (Cabanes, 2009). Essas "disposições femininas" "vão de encontro com as políticas de valores 'familistas'29 (Esping-Andersen, 2008; Mioto, 2010) em curso na América Latina, refletindo tendência internacional contemporânea" (Georges; Santos, 2016: 156).

Com base em abordagem interacionista da análise das instituições ${ }^{30}$ e na análise clássica de Howard S. Becker (2008) sobre a atividade dos "empreendedores morais" e sobre o "desvio" social, a trajetória institucional da Fundação Paixão foi interpretada como empresa moral.

Uma das especificidades dessa abordagem é a continuidade entre a instituição e seus 'usuários', entre estar 'dentro' e 'fora', isto é, a fluidez das 'fronteiras', permitindo a investigação da dinâmica institucional no contexto da terceirização em questão. Nessa perspectiva, trata-se de compreender as dinâmicas institucionais e formas de legitimação que levam à consolidação de uma organização a partir de uma convicção moral inicial, a assim chamada 'cruzada moral'. Nesse empreendimento, a legitimação moral da ideia é crucial e depende da atividade dos 'empreendedores morais', que atuam como os 'criadores de regras' (Georges; Santos, 2016: 156-157).

Nesse sentido, há três argumentos principais que fundamentam a interpenetração entre as carreiras das "empreendedoras morais" (as gestoras das entidades) e a própria trajetória da instituição, garantindo seu sucesso:

1) A construção do gênero das carreiras sociais na Fundação Paixão permite às mulheres realizar uma carreira profissional ascendente, apesar do salário abaixo dos valores de mercado, mesmo em nível de gerência. A carreira profissional e sua intermitência por causa da maternidade, ou seu caráter tardio, depois do acesso aos estudos num estágio mais avançado da vida, não é reivindicada como tal e permanece aparecendo, em suas representações, como continuidade do trabalho voluntário. Esses elementos evitariam a

\footnotetext{
${ }^{29}$ Políticas "familistas" amplamente adotadas nos programas sociais contemporâneos no Brasil e em outros países da América Latina. Tais abordagens contam com a ativa participação das famílias para o provimento do bem-estar à população pobre, tendo como principal interlocutor a mulher na condição de mãe, esposa, avó, filha mais velha etc. Seus objetivos são em última instância o combate à pobreza intergeracional, as crianças sendo alvo do investimento social, por intermédio da participação e cumprimento responsável do conteúdo dos programas, na maioria dos casos, pela mãe Molyneux (2006: 433) e Jenson (2011: 23).

${ }^{30}$ Essa abordagem destaca a oferta institucional para compreender o funcionamento das organizações num sentido amplo Hughes (1984) e Briand e Chapoulie (1992).
} 
concorrência com o trabalho e posição social de seus maridos, e estimulariam a priorização da reivindicação de utilidade social do trabalho, em detrimento do seu caráter profissional.

2) Nesse contexto de relações de gênero baseadas na divisão sexual tradicional do trabalho, essa abordagem estaria em concordância com a conjuntura política atual do município (e do estado) de São Paulo: a terceirização dos serviços sociais tornaria as expectativas salariais e profissionais das mulheres compatíveis com a oferta institucional de emprego precário, de nível salarial abaixo do mercado, condicionada por esse sistema.

3) O discurso sobre a "transformação social" da população assistida, que justificaria a própria atuação da Fundação, tornando dispensável e inviabilizando qualquer forma de reivindicação política, posição facilitada também pela origem social comum entre as "empreendedoras" e a população atendida, assim como por seu papel social de cônjuge dependente.

De modo complementar, a operacionalização do programa de assistência (PAS - SASF) constituiria a atividade dos "impositores de regras", ou seja, dos agentes de rua. "[...] as mulheres 'assistidas', titulares do Programa, são o alvo da atividade de moralização e, de forma declarada pela organização, de transformação social, razão de ser da entidade. Todavia, a adesão (ou não) a tais valores morais é função da 'carreira moral' empenhada por cada atriz social" (Georges; Santos, 2013: 160) - ou seja, da carreira moral de trabalhadoras em diversos níveis hierárquicos, das agentes de execução até as usuárias/beneficiárias do programa.

Um conjunto de práticas institucionais, assim como seu discurso fundador, justificariam a razão de ser da instituição, bem como a seleção de uma parte dos usuários potenciais, passando pela profissionalização do trabalho dos "empreendedores morais" até a criação de uma "empresa moral". Esse processo constituiria um exemplo concreto do "governo moral dos pobres" como analisado por Bruno Lautier (2009, 2014) num plano mais geral. Tal governo opera através das práticas classificatórias, entre "bons" pobres e "maus" pobres, tarefa que passa pelas práticas de trabalhadores da assistência, no âmbito das instituições que desenham suas próprias regras morais. Intensificada pela terceirização dos programas e serviços em São Paulo, a tecnicização e burocratização do serviço conduziria a um obscurecimento da própria ideia de "direito" do(a)s usuário(a)s, reconfigurado(a)s quer como público-alvo das entidades quer como mercado, permitindo às entidades gestoras assegurar sua posição de prestadoras de serviço que garantem seu lugar frente à cesta de ofertas do poder público.

Instâncias de ordenamento concorrentes e regimes de moralidade liminares: tudo junto e tudo misturado

A normalização e capilaridade das experiências próximas ao "mundo do crime" apareceram nas falas recolhidas e situações de pesquisa sistematizadas em vários momentos e a partir de objetos diversos, como a fala que se segue, de 
uma futura beneficiária do PMCMV-Entidades: "Meu marido foi morto - vou logo dizendo. Foi morto porque fazia coisa errada. Eu tinha dois filhos e uns 20 e poucos anos quando ele foi morto". Esmeralda, participante de um grupo do PMCMV-Entidades - abril de 2014, quando apontou que sua alternativa de moradia e sustento foi mudar para o quintal da casa dos sogros, no extremo sul da cidade de São Paulo. Também seria possível relatar a "consciência dos momentos de vacilo" ou mesmo cenas do trabalho cotidiano dos agentes culturais nas atividades que se pautam pela oposição práticas culturais x mundo do crime ${ }^{31}$.

Assim também, em dezembro de 2012 - caminhando em atividade de acompanhamento de visita domiciliar com uma agente comunitária de saúde sexta-feira, pouco depois das 12 horas, essa agente perguntou à pesquisadora: "a senhora não se importa de ser filmada, não é? A senhora acabou de ser filmada". E, mais uma vez, pouco tempo depois: "Também não se importa de ser fotografada, não é? Também acabou de ser fotografada. É que hoje é sextafeira à tarde. É dia do vale coxinha... quando a polícia chega pra cobrar a parte dela. Aífica assim meio complicado..."

Essa mesma agente, contato de várias equipes de pesquisa graças à disponibilidade para receber pesquisadores e por mostrar como conhecia bem o bairro e as famílias atendidas, alertou sobre uma grande quantidade de indícios e de sinais visuais, sonoros, gestuais que foram completamente despercebidos pela equipe de pesquisadores. Talvez por um contato cotidiano e muito provavelmente familiar com o tráfico, Imaculada pôde me mostrar o que ela via e o que nós não víamos, em um procedimento corriqueiro de acompanhamento e visita às famílias. Também nesse âmbito, uma dimensão visivelmente territorial se anunciava - sobretudo um modo de ler esses sinais, índices e pistas que nasce de práticas e de modos de agir, das tramas e das relações pouco visíveis para quem, ainda que aceito, não pertenceria àquele território, não é parte daquela construção de práticas, redes, afetos e fluxos. Seria ainda possível indicar outros exemplos que parecem apontar o que Feltran (2011) mostrou a partir das suas evidências empíricas.

Tal como já se observou (Georges; Santos, 2016, capítulo 10), a análise da trajetória dessa agente comunitária demonstra a convivência e a utilização pendular de um conjunto de quadros de referência de conduta, quadros paralelos, que possibilitaram, diante de um conjunto de dificuldades e urgências, que ela reassumisse o domínio sobre o seu destino e encontrasse saídas "de emergência”32.

Imaculada entrou no serviço público por intermédio de uma das organizações sociais terceirizadas do Programa Saúde da Família, no momento da generalização deste na cidade de São Paulo, no início dos anos 2000. [...]. No plano diacrônico, seu percurso atravessa este universo (o 'mundo do crime') como no plano sincrônico, onde ela negocia permanentemente essas práticas profissionais com a instância de ordenamento da vida cotidiana do bairro (Georges; Santos, 2016, capítulo 10).

\footnotetext{
${ }^{31}$ Ver Rizek (2016).

${ }^{32}$ Referência ao livro de mesmo nome, organizado pelas autoras e por Cabanes et al. (2011).
} 
As vicissitudes e urgências, a viração e o restabelecimento das condições de sobrevivência, presentes nesse percurso de mais de 50 anos, permitem compreender como diferentes lógicas e códigos morais, aparentemente antagônicos, de fato coexistiriam. Nos meandros dessa coexistência, muitas vezes aparentemente labiríntica, é possível perceber como situações sombrias seriam superadas, como as emergências quase contínuas seriam contornadas, como se pode constatar na descrição a seguir:

Para salvar seu irmão "de uma morte inevitável na cadeia”, Imaculada compra (sua) proteção [...], aceitando se tornar amante de um conhecido traficante, encarcerado com ele. Na saída do irmão da prisão, ela tentaria se separar, mas o amante acaba fugindo e (a) ameaça [...] e à família de morte. Consequentemente, ela aceita casar-se com ele em 1979, aos seus 21 anos e a sua primeira filha nasce no ano seguinte. Beneficiado pelo indulto no momento do nascimento, ele retornaria à cadeia da qual sairia somente dez anos mais tarde (em 1989). Durante este período, como esposa, Imaculada recebe auxílio do Estado, destinado às famílias de detentos (auxílio reclusão). Na saída do marido da prisão, a família se transferiria para Santos, onde o pai de sua filha, chaveiro, especializa-se no roubo de cofres-fortes e retoma o tráfico de entorpecentes. Imaculada se distancia do marido, embora ressalve que 'ele era bom (para ela)'. As idas e voltas à prisão prosseguem, entretanto ... (e) Imaculada recusa-se a participar como intermediária para introduzir entorpecentes na prisão [...] os contatos com o ex-marido são reduzidos a visitas esporádicas da filha, levada por uma tia (pois o ex-marido havia retirado Imaculada da lista dos visitantes). Ele morreria de AIDS na cadeia, deixando diversos bens materiais (imobiliários) para Imaculada e para a filha; bens que foram recusados por ambas. Durante o período de detenção de seu primeiro marido, Imaculada recomporia a vida com outro homem, pai de sua segunda filha,... (ele a abandona em 2007). Nascida em 1988 (aos 30 anos de Imaculada), a filha vive com ela até hoje, juntamente com duas netas gêmeas, nascidas em 2009, e o seu genro (é) cozinheiro em uma cafeteria. A filha completou o ensino médio, tendo sido operadora de telemarketing em 2011 e, em seguida, caixa no supermercado do bairro. $O$ pai da segunda filha de Imaculada é trabalhador; à época empregado de estacionamento e atualmente entregador. Imaculada morava em um pequeno apartamento alugado nas proximidades do presídio, na periferia Norte da capital, onde transcorre a vida da nova família. Nesse período, Imaculada trabalha como secretária em diferentes empresas da indústria automobilística, em um supermercado (entre 1986 e 1989, com carteira assinada) e como responsável pelos caixas, entre 1994 e 1997. No momento da venda do supermercado para um grupo multinacional, ela pede demissão (o desligamento constitui um momento privilegiado para sacar o "fundo de garantia") com vistas a abrir um negócio próprio juntamente com o marido, à época, desempregado. A empresa de produtos de limpeza [...] e o caminhão de entrega estão no nome de Imaculada. A empresa vende bem durante um ano e eles faturam bastante. Imaculada ocupa-se dos produtos e o seu marido dirige o caminhão até o momento em 
que a abandona [...]. Em seguida, viria a decadência: Imaculada continua com um motorista contratado, mas acaba por vender o negócio, passando a trabalhar como empregada doméstica. Ela seria expulsa de seu apartamento em razão de aluguéis atrasados. É gratuitamente abrigada em Guaianazes, periferia Leste da cidade de São Paulo, por um advogado, empregador de sua primeira filha (emprego conseguido pelo pai da jovem). Em 1999, aos 41 anos, ela compra, com o fundo de garantia da primeira filha, uma casa nos confins da capital, no bairro Cidade Tiradentes (extremo Leste da cidade de São Paulo) (Georges e Santos, 2016, capitulo 10).

A trajetória de Imaculada ilustra, ao lado de outras falas em outras situações de pesquisa sobre programas de moradia ou agentes de cultura, essa capilaridade e normalização, esse vaivém de práticas que compõem os territórios que conformam a vida das populações-alvo e dos agentes que operacionalizam na ponta as políticas sociais. Talvez seja mesmo impossível compreender os desdobramentos e dimensões dessas políticas sem compreender essas dimensões de dobra, as oscilações e utilizações pendulares dos códigos e instâncias morais e de governo, no quadro de um conjunto nada evidente de relações de força, de modos e práticas de resistência e, ao mesmo tempo, de instrumentalização da cesta ou do quadro de referências, serviços, bens, virações, relações que vêm compondo as práticas cotidianas da reconfiguração da pobreza no Brasil.

\section{Conclusão}

A partir do cruzamento de várias temáticas de pesquisa - o trabalho, as privatizações, a captação da demanda e os regimes morais -, esse experimento coletivo de pesquisa acabou por fazer emergir um novo objeto: aquele "social" reconfigurado que se constitui como uma das características principais das formas de governo dos anos 2000. Um dos traços principais desse dispositivo de governo que garantiu uma certa governamentalidade durante mais ou menos uma década é seu caráter híbrido, pouco nítido, de junção inédita entre reconhecimento da demanda social, políticas sociais e mercado, provocando uma transformação pouco evidente da política (social) em negócio. Nesse sentido, o trabalho pôde ser apreendido como resultado do processo de criação de informalidades, impulsionado, entre outros atores, pelo Estado; as privatizações de certos setores deram lugar a um planejamento social privado; a "demanda" da população, ou a demanda social, ocupou o lugar da "participação" e acaba por legitimar as entidades que participam desse novo mercado do social; e, atravessado e recriado pelas trajetórias, este novo meio social dá lugar a um conjunto de moralidades cuja característica principal parece ser o seu entrelaçamento. $O$ seu resultado concreto é o encolhimento do conflito, o desaparecimento das posições divergentes e das relações de poder entre indivíduos e coletivos, esvaziadas do seu sentido, em favor de um empreendedorismo e empresariamento que se instaurou como valor dominante e, principalmente, estruturante. Dessa forma, esperamos ter mostrado 
como concretamente e a partir do trabalho de campo dominação e apropriação, dispositivos e agenciamentos, dimensões funcionais, como nós de circuitos e representações e discursos, se articularam em uma riqueza que talvez apenas a imersão nas dimensões percebidas e vividas, talvez apenas pelos contrapontos entre regimes de enunciação e visibilidade possam ser apreendidas.

\section{Referências}

BECKER, Howard Saul. Outsiders: estudos de sociologia do desvio. Rio de Janeiro, Zahar, 2008. Original de 1963.

BIRMAN, Patricia et al. Dispositivos urbanos e trama dos viventes: ordens e resistências. Rio de Janeiro, FGV Editora, 2015.

BRAGA, Ruy. A política do precariado. São Paulo, Boitempo, 2012.

BRASIL. Ministério da Cultura, Secretaria de Cidadania Cultural. Edital de divulgação № 2, de 08 de março de 2010. Diário Oficial da República Federativa do Brasil, Brasília, DF, 07 de julho de 2004.

. Ministério da Cultura, Secretarias de Programas e Projetos Culturais. Edital de divulgação № 3, de 06 de agosto de 2008: prêmio cultura e saúde. Diário Oficial da República Federativa do Brasil, Brasília, DF, 07 de agosto de 2008.

BRIAND, Jean-Pierre; CHAPOULIE, Jean-Michel. Les collègues du people. Paris, INRPCNRS-ENS, 1992.

BURAWOY, Michael. Global etnography, forces, connections and imaginations in a postmodern world. Berkeley, University of California Press, 2000.

CABANES, Robert et al. Saídas de emergência: perder/ganhar a vida em São Paulo. São Paulo, Boitempo Editorial, 2011.

CABANES, Robert. Quelle dialectique possible entre espace privé et public? In: CABANES, Robert; GEORGES, Isabel. (Orgs.). São Paulo, la ville den bas. Paris, l'Harmattan, 2009, pp .421-455.

DESTEMAU, Blandine; GEORGES, Isabel. Gouverner les pauvres en Amérique latine: gérer les femmes par l'assistance. In: DESTREMAU, Blandine; GEORGES, Isabel (Orgs.). Le care, nouvelle morale du capitalisme. Assistance et police des familles en Amérique latine. Aix-en-Provence, Karthala et SciencesPo, 2016, no prelo.

ESPING-ANDERSEN, Gøsta. Trois leçons sur l'Etat-providence. Paris, Seuil, 2008.

FELTRAN, Gabriel de Santis. Fronteiras de tensão. Política e violência nas periferias de São Paulo. São Paulo, Ed. Unesp, 2011.

GEORGES, Isabel. Entre participação e controle: os(as) agentes comunitários de saúde da região metropolitana de São Paulo. Sociedade e Cultura, Goiânia, v. 14, n. 1, Jan./ Jun. 2011, pp. 73-85. 
Informalidades do Estado e dispositivos de ordenamento: uma abordagem territorial, setorial e comparativa. In: $38^{\circ}$ Encontro Anual da ANPOCS. Caxambú Minas Gerais: hotel Glória, 2014.

. Les revers de la formalisation dans le travail du care au Brésil. Studi di Sociologia, Milano, v. 3, 2015, pp. 299-312.

GEORGES, Isabel; RIZEK, Cibele Saliba. A periferia do direito: trabalho, precariedade e políticas públicas. In: $32^{\circ}$ Encontro Anual da ANPOCS. Caxambu, Minas Gerais: hotel Glória, 2008.

. À la périphérie des droits: travail, précarité et politiques publiques. In: GEORGES, Isabel; LEITE, Marcia de Paula (Orgs.). Les nouvelles configurations du travail et l'Économie sociale et solidaire au Brésil. Paris, l'Harmattan, 2012, pp. 65-88.

GEORGES, Isabel; RIZEK, Cibele Saliba; CEBALLOS, Marco. As políticas sociais brasileiras: o que há de novo? In: GEORGES, Isabel; RIZEK, Cibele Saliba; CEBALLOS, Marco (Orgs.). Coordination du dossier. As politiquas sociais brasileiras. Caderno CRH, Salvador, v. 27, n. 72, Dec. 2014, pp. 457-461.

GEORGES, Isabel; SANTOS, Yumi Garcia. A produção da "demanda": viés institucional e implicações políticas da terceirização do trabalho social. In: $35^{\circ}$ Encontro Anual da ANPOCS, Caxambu Minas Gerais: hotel Glória, 2011.

. Care e políticas públicas: o caso das "agentes comunitárias de saúde” e das "agentes de proteção social. In: HIRATA, Helena; GUIMARAES, Nadya Araújo (Orgs.). Cuidado e cuidadoras: as varias faces do trabalho do care. São Paulo, Ed. Atlas, 2012, pp. 166-182.

. A produção da "demanda": viés institucional e implicações políticas da terceirização do trabalho social na periferia de São Paulo. In: CUNHA, Neiva Vieira da; FELTRAN, Gabriel de Santis. Sobre periferias: novos conflitos no espaço público, Rio de Janeiro, Ed. Faperj/Lamparina, 2013, pp. 159-177.

As novas políticas sociais brasileiras na saúde e na assistência. Produção local de serviço e relações de gênero. Belo Horizonte, Fino Traço, 2016, no prelo.

GEORGES, Isabel; SILVA, Carlos Freire. A naturalização da precariedade: trabalho informal, autônomo e cooperativado entre costureiras em São Paulo (Brasil). In: LIMA, Jacob Carlos (Ed.). Ligações perigosas: trabalho flexível e trabalho associado. São Paulo, Editora Annablume, 2007, pp. 285-311.

GLASER, Barney G.; STRAUSS, Anselm L. The discovery of Grounded Theory: strategies for qualitative research. Chicago, Aldine Publishing Company, 1967.

HUGHES, Everett Cherrington. Going concerns: the study of American Institutions. In: HUGHES, Everett Cherrington. The sociological Eye. Chicago, Aldine Publishers, 1984.

JENSON, Jane. Politiques publiques et investissement social: quelles conséquences pour la citoyenneté sociale des femmes?. In: MARQUES-PEREIRA, Bérengère; PFEFFERKORN, Roland. (Orgs.). Genre, politiques sociales et citoyenneté. Cahiers du Genre. Paris, L'Harmattan, 2011, pp. 21-43. 
KERGOAT, Daniele et al. (Orgs.). Les infirmières et leur Coordination, 1988-1989. Paris, Éditions Lamarre, 1992.

LAUTIER, Bruno. Gouvernement moral des pauvres et dépolitisation des politiques publiques en Amérique latine. In: BORGEAUD-GARCIANDÍA, Natacha; LAUTIER, Bruno; PEÑAFIEL, Ricardo; TIZZIANI, Ania (Orgs.). Penser le politique en Amérique Latine: La recréation des espaces et des formes du politique. Paris, Karthala, 2009, pp. 19-36.

. O governo moral dos pobres e a despolitização das políticas públicas na América Latina. Caderno CRH, Salvador, v. 27, n. 72, 2014, pp. 463-477.

MACHADO DA SILVA, Luiz Antônio, O Eterno retorno ao informal: categorias resilientes, realidades desafiadoras, abordagens heterodoxas. In: Congress of the Latin American Studies Association (LASA), Chicago, IL: Library of Congress. 2014.

MIOTO, Regina. A família como referência nas políticas públicas: dilemas e tendências. In: TRAD, Lab (Org.). Família contemporânea e saúde: significados, práticas e políticas públicas. Rio de Janeiro, Fiocruz, 2010, pp. 51-66.

MOLYNEUX, Maxine. Mothers at the service of the New Poverty agenda: progresa/ oportunidades, Mexico's conditional transfer programme. Social Policy and Administration, Oxford, v. 40, n. 4, 2006, pp. 425-449.

REVEL, Jacques. Jeux d’échelles. La Microanalyse à l'expérience. Paris: Gallimard, 1996.

RIZEK, Cibele Saliba. Verde amarelo azul e branco: o fetiche de uma mercadoria ou seu segredo. In: OLIVEIRA, Francisco; BRAGA, Ruy; RIZEK, Cibele Saliba (Orgs.). Hegemonia às avessas. São Paulo, Boitempo Editorial, 2010, pp. 215-236, v. 1.

. Trabalho, moradia e cidade Zonas de indiferenciação?. Revista Brasileira de Ciências Sociais, São Paulo, v. 27, n. 78, 2012, pp. 41-50.

. Políticas Sociais e Políticas de Cultura: territórios e privatizações cruzadas. Revista Brasileira de Estudos Urbanos e Regionais, Recife, v. 15, 2013, pp.199-209.

. Faces do Lulismo: políticas de cultura e cotidiano na periferia de São Paulo. In: SINGER, André; LOUREIRO, Isabel (Coord.). Desigual e combinado, capitalismo e modernização periférica no Brasil. São Paulo, Boitempo Editorial, 2016, no prelo.

RIZEK, Cibele Saliba; CARVALHO, C. S.; CAMARGO, Camila Moreno. Política social, gestão e negócio na produção das cidades: o Programa Minha Casa Minha Vida Entidades. Caderno CRH, Salvador, v. 27, n. 72, 2014, pp. 531-546.

RIZEK, Cibele; GEORGES, Isabel; SILVA Carlos Freire. Labour and migration patterns: the clothing industry and bolivian migrants. In: FAKIER, Khayaat; EHMKE, Ellen (Orgs.). Socio-economic insecurity in emerging economies: building new spaces. Local de publicação, Routledge Explorations in Development Studies, 2014, pp. 44-55.

SANTOS, Yumi Garcia. Família, trabalho e religião das mulheres assistidas em São Paulo. Cadernos de Pesquisa da Fundação Carlos Chagas. v. 44, n. 152, 2014, pp. 400-421.

SÃO PAULO. Prefeitura. Resultados parciais do censo demográfico 2010 para o município de São Paulo. Boletin CEInfo Informativo Censo Demográfico 2010, n. 2, Julho 2012, pp. 1-9. Disponível em: <http://www.prefeitura.sp.gov.br/cidade/secretarias/ 
upload/saude/arquivos/publicacoes/Boletim_CEInfo_Censo_02.pdf>. Acesso em: 01 maio 2012.

SHIMBO, Lucia Zanin. Habitação social de mercado. Belo Horizonte, Ed. c/Arte, 2012.

SILVA, Carlos Freire. Trabalho informal e redes de subcontratação: dinâmicas urbanas da indústria de confecções em São Paulo. Dissertação de mestrado, Sociologia, Universidade de São Paulo, 2008.

Recebido em: 18/03/2016

Aprovado em: 18/04/2016

\section{Como citar este artigo}

GEORGES, Isabel Pauline Hildegard; RIZEK, Cibele Saliba. Práticas e dispositivos: escalas, territórios e atores. Contemporânea - Revista de Sociologia da UFSCar. São Carlos, v. 6, n. 1, jan.-jun. 2016, pp. 51-73. 